\title{
Factors and conditions promoting academic resilience: a TIMSS- based analysis of five Asian education systems
}

\author{
Andrés Sandoval-Hernández ${ }^{1,2} \cdot$ Piotr Białowolski $^{1,3}$ (D)
}

Received: 14 September 2015/Revised: 29 June 2016/Accepted: 19 July 2016/Published online: 28 July 2016

(C) The Author(s) 2016. This article is published with open access at Springerlink.com

\begin{abstract}
It is well documented that academic achievement of students from families of low socioeconomic status (SES) tends to be below their more socially advantaged peers. Several studies have identified factors and conditions that facilitate academic success for disadvantaged students (i.e., promote academic resilience). However, one of the main criticisms of this body of research is in the set of variables that explain academic success for low-SES students and which is not very different from the variables that would explain academic success for all students. The objectives of this article are dual: firstly, to identify factors and conditions associated with academic success, regardless of student SES, and secondly, to identify factors and conditions associated with academic resilience, that is, exclusively for low-SES students. To this end, we used data from Singapore, South Korea, Hong Kong, Chinese Taipei, and Japan in the Trends in International Mathematics and Science Study (TIMSS) 2011. The study sample covered 23,354 students in 720 schools in the five countries. The strategy for analysis was driven by fit of logistic regression models, first predicting the probability of academic success and then subsequent identification of variables significant as predictors for success within the pool of low-SES students. Results indicated that variables, such as positive student attitude to mathematics, teacher confidence in student performance and the test language being
\end{abstract}

Piotr Białowolski

piotr.bialowolski@sgh.waw.pl

1 Data Processing and Research Center, International Association for the Evaluation of Educational Achievement, Hamburg, Germany

2 University of Bath, Bath, UK

3 Warsaw School of Economics, Warsaw, Poland spoken at home, were associated with greater chances of academic success. High academic expectations and time spent on mathematics at home demonstrated a differential effect between disadvantaged and non-disadvantaged students in Singapore. In Korea, being male (gender) and in Taipei, low levels of bullying at school, increased the likelihood of resilience. Results suggested that interventions impacting behavior reflected in differentially associated variables could help disadvantaged students to become academically resilient.

Keywords Academic resilience - Educational achievement $\cdot$ Socioeconomic status · TIMSS

\section{Introduction}

Internationally comparable large-scale assessments have shown that students from low-socioeconomic status (SES) families tend to be out-performed at school by their more socially advantaged peers (Mullis et al. 2012). However, several studies have shown that in most countries a group of children is academically successful despite the challenge of their backgrounds (Borman and Overman 2004; Cheung et al. 2013; Martin and Marsh 2006; OECD 2011). These students are termed resilient. In other words, resilient students are those who are academically successful but come from socioeconomically disadvantaged backgrounds. This general definition has been adopted in most articles reporting resilient students and has normally been operationalized using an index of socioeconomic status to determine disadvantage status and a test score to register academic success (see, for example, Cheung et al. 2013; Erberer et al. 2015; OECD 2011). 
The study of academic resilience is not new, and there is a significant body of research on the subject. Previous attempts to identify variables associated with academic resilience have nevertheless suffered from important limitations. First, studies on academic resilience often focus solely on the group of socially disadvantaged students (Agasisti and Longobardi 2014; Borman and Overman 2004; Erberer et al. 2015; Graves 2014; OECD 2011), risking the trap of identifying factors associated with educational achievement in general, while failing to identify those only associated with resilience. This is a very important consideration, since in the transformation of these findings into policies or interventions, the promotion of factors that improve disadvantaged students' academic achievement could simultaneously, to a greater extent, improve the performance of non-disadvantaged students. The result would be to widen the prevailing academic gap between disadvantaged and non-disadvantaged students prior to intervention. A second limitation of many previous studies on academic resilience is that they tend to focus on specific settings (e.g., a group of schools in a district). This approach restricts generalization of results to broader populations and introduces problems to investigation of system level characteristics as promoters of resilience. Finally, a third limitation is that most of these studies, especially those using international comparative data, lack a sound theoretical basis that would support the interpretation of their findings (cf. Agasisti and Longobardi 2014; Cheung et al. 2013; Erberer et al. 2015; OECD 2011).

In this work, these limitations were overcome by, first, using a statistical technique that allowed differentiation of factors only associated with resilience from those related to educational achievement in general. Second, data from a large-scale international assessment allowed comparison of findings between education systems. In order to improve the comparability of results, data from education systems located in the same geographical area with similar socioeconomic conditions and levels of educational achievement were analyzed. Thirdly, the cultural-ecological transaction model of resilience (Kuperminc et al. 2009) was employed to assist in the interpretation of findings.

In this way, the main objectives of this work were:

(1) To identify the factors and conditions associated with academic success (regardless of student socioeconomic background) in the education systems investigated.

(2) To differentiate factors and conditions exclusively associated with academic success of socially disadvantaged students (i.e., academic resilience).

In the following section of this paper, we outline the basis of our theoretical framework.

\section{A model of educational resilience}

The origins of resilience theory can be traced back to psychological studies from the first half of the twentieth century (Hill 1958). However, for the past three decades, the field has broadened and studies of resilience have been carried out by social workers, sociologists, educators and policy makers (Van Breda 2001). Since this paper is concerned with academic resilience in five Asian countries, a culturally relevant theory is applied to help explain academic resilience of students in these countries, i.e., the cultural-ecological transactional perspective developed by (Kuperminc et al. 2009).

The cultural-ecological transactional perspective was developed as a response to criticism of the ecologicaltransactional model developed by Bronfenbrenner (1979). Specifically, (Kuperminc et al. 2009) argued that, when applied to collectivist cultures, Bronfenbrenner's model underestimated the means by which cultural factors contributed to individual development.

The ecological-transactional model emphasizes the influence of multiple systems on human development, at individual, micro-, meso-, exo- and macro-system levels. These systems accommodate individual characteristics from age and gender (individual system), to broader cultural beliefs and values, such as the socially attributed value of education (macro-system). Influence of individual and micro-systems on individual development is direct in this model, while it is only indirect for the other cases. Here, explanations offered by Kuperminc et al. diverge from Bronfenbrenner. The cultural-ecological transactional model proposes that in the analysis of more interdependent cultures, like those of the Asian countries included in this study, sociocultural factors must play a more prominent role since they do not only have indirect influence. This model postulates constant interaction of sociocultural factors at the individual level, thus playing a proximal role. As (Piña-Watson et al. 2013) explain, through the use of this model, cultural processes that children experience can be accounted for in a way that reflects dynamic and proximal relationships between the different component systems.

Kuperminc et al. (2009) asserted that issues of minority status in countries such as those analyzed here, i.e., socioeconomic stratification, gender roles, immigration status, language spoken in the home and the socially assigned value of education, were determinants of the context in which children live. This should be interpreted as, the schools, classrooms, teacher and parent expectations about attainment and ultimately educational achievement itself. Furthermore, the authors agree that the cultural beliefs and values associated with these factors form the "lens" through which children perceive their own context and 
develop strategies to meet the challenges and opportunities within their education system and beyond.

The remaining paper is organized as follows: First, we describe the data and the methodological approach applied to the analysis. Then, we present our findings, followed by a discussion of its implications in the final part.

\section{Data and methods}

\section{Data}

Data were drawn from the Trends in International Mathematics and Science Study (TIMSS) 2011 conducted by the International Association for the Evaluation of Educational Achievement (IEA). The target for TIMSS was the student population completing the fourth and eighth grades in 63 countries and 14 regional jurisdictions. Samples were representative at the education system level. Besides assessing mathematics and science achievement, TIMSS also covers information about students, teachers and school characteristics (Mullis et al. 2012). ${ }^{1}$ For the purpose of this study, analysis was limited to Grade 8 mathematics attainment in five Asian education systems: Chinese Taipei, Hong Kong, Japan, the Republic of Korea and Singapore. These education systems were chosen because they lay in the same geographical region and therefore shared some historical and socio-cultural characteristics. ${ }^{2}$ They are also similar in socioeconomic contexts and regarded as consistent top performers in TIMSS and other international student assessments. Table 1 presents the sample distribution for the education systems considered in the analysis.

\section{Method}

A common approach to the study of academic resilience which is adopted in quantitative studies involves fitting logistic regression models to a subsample of socially disadvantaged students and estimation of their likelihood of having developed resilience according to a defined set of predictors (Cheung et al. 2013; Erberer et al. 2015). This is a well-established and generally accepted procedure. However, since only a subsample of disadvantaged students is analyzed, it is not possible to evaluate the potential differential discriminatory effect of predictors on non-disadvantaged students, i.e., the remaining population of the sample. A logical means to overcome this limitation is to fit

\footnotetext{
$\overline{1}$ TIMSS data are publicly available and can be downloaded from the IEA's website-www.iea.nl.

${ }^{2}$ For example, they all can be considered collectivist following Hofstede (1984).
}

the same model to the subsample without disadvantaged and then to compare regression coefficients.

Comparison of logistic regression coefficients, however, is not a straightforward operation as it would be in the case of linear models. In fact, such comparisons demand a complex procedure, since the dependent variable is a latent construct and its identification is only achievable by constraint of the residual to the logistic distribution. The standard logistic model—following Williams (2010)—can be presented as follows.

$y_{i}^{*}=\alpha_{0}+\alpha_{1} x_{i 1}+\ldots+\alpha_{k} x_{i k}+\sigma \varepsilon_{i}$

where $y_{i}^{*}$ is the latent variable which is a collapsed version of underlying variable $y_{i}$ and takes values 0 if $-\infty<y_{i}^{*}<\kappa$ and 1 if $\kappa<y_{i}^{*}<+\infty$. Additionally, the error variance follows logistic distribution with variance of $\varepsilon_{i}$ constrained to $\pi^{2} / 3$ (cf. Williams 2010). The consequence of this is that $\alpha_{i}$ 's cannot be estimated in a straightforward way owing to the variance constraint. Instead, all the terms in Eq. (1) are divided by $\sigma$ and in the model suitable for estimation, $\beta_{i}$ 's satisfying the condition $\beta_{i}=\frac{\alpha_{i}}{\sigma}$ are estimated.

Comparison of $\beta_{i}$ 's is obviously possible between models, but if $\sigma$ is unknown, such a comparison informs little about differences in $\alpha_{i}^{\prime}$ 's. Additionally, when $\sigma$ differs between groups, the problem of heteroscedasticity emerges, and even the ratios of $\beta_{i}$ 's for a given $i$ are not comparable between models. A solution to this problem lies in the simultaneous estimation of $\beta_{i}$ 's and $\sigma$, with $\sigma$ being defined by predictors used in the model.

One approach to handle this issue is based on heterogeneous choice models and was first presented by Allison (1999) and later developed by Williams (2010). The heterogeneous choice models accomplish comparability of coefficients by simultaneously fitting two equations-one for the determinants of the outcome and the other for variance. $^{3}$ An additional advantage of heterogeneous choice models is that they account for the heterogeneity between the groups being compared in the outcome variable (i.e., likelihood of academic success). This study exploited this approach to compare the strength of different predictors on the likelihood of academic success for disadvantaged and non-disadvantaged students.

While being fully cognizant that TIMSS data are nested in nature and that a common method to deal with this issue involves the use of multilevel regression models, the decision was made not to adopt this approach, owing to the present lack of software which would allow the running of heterogeneous choice models with multilevel regression. Instead, jackknife variation estimation procedures were

\footnotetext{
${ }^{3}$ Details for the specification and estimation of the heterogeneous choice models are explained in detail by Williams (2010).
} 
Table 1 Distribution of the sample

\begin{tabular}{|c|c|c|c|c|c|c|}
\hline \multirow[t]{2}{*}{ Education system } & \multirow[t]{2}{*}{ School sample size } & \multirow[t]{2}{*}{ Student sample size } & \multicolumn{2}{|c|}{ Proportion of socially disadvantaged students } & \multicolumn{2}{|c|}{ Proportion of resilient students } \\
\hline & & & $\%$ & SE & $\%$ & SE \\
\hline Taipei & 150 & 4284 & 12 & 0.67 & 51 & 2.60 \\
\hline Hong Kong & 117 & 3957 & 19 & 0.83 & 54 & 3.50 \\
\hline Japan & 138 & 4411 & 5 & 0.48 & 55 & 5.20 \\
\hline Republic of Korea & 150 & 4334 & 4 & 0.31 & 50 & 3.90 \\
\hline Singapore & 165 & 6368 & 12 & 0.62 & 52 & 3.70 \\
\hline
\end{tabular}

used, with replicate weights to reflect the nested data structure (Olson et al. 2008). Additionally, to accommodate the complex assessment design of TIMSS, all regression models were fitted using sampling weights and, when applicable, plausible values. ${ }^{4}$

\section{Modeling strategy}

In research on resilient students, one of the most interesting questions posed is whether certain factors that prove important for academic achievement in general should be considered particularly relevant to the achievement of the disadvantaged student group. In order to address this point, heterogeneous choice logit models initiated the estimation of the likelihood of student academic success based on a predetermined set of predictors. Subsequently, models were estimated which comprised not only standard covariates, but also interactional terms that allowed distinction between the differential effects of the predictors on disadvantaged and non-disadvantaged students. More specifically, the strategy included the following steps:

Firstly, models were estimated to predict the likelihood of student academic success, including all preselected covariates for each education system-simultaneously accounting for heterogeneity of variance between disadvantaged and non-disadvantaged students. Then, without excluding any nonsignificant covariates, the search was for significant indicators of academic success in one group only (either disadvantaged or non-disadvantaged students).

Candidate variables for explanation of academic success in the disadvantaged group were selected using the Akaike Information Criterion (AIC). ${ }^{5}$ Secondly, variables were selected which generated lower information criteria estimates than the reference model after inclusion (without any interactions). The best candidate variable was subsequently

\footnotetext{
${ }^{4}$ Details on the sample and assessment design of TIMSS can be found in http://timss.bc.edu/methods/

5 Due to the non-availability of a statistical procedure to estimate AIC while considering multiple imputation, only the first plausible value of the achievement score was used in this procedure.
}

included, and the model was run. That is, if the $p$ value for at least one estimate was below 0.1 , then this variable was included in the model. If no variable met this criterion, the second best alternative was tried. The procedure was repeated until there were no remaining plausible candidates.

\section{Measures}

The model proposed by (Erberer et al. 2015) recommended the set of explanatory variables included in the analysis. This set of variables was considered justifiable, being deeply embedded in both the literature on academic resilience and the TIMSS Contextual Framework (Mullis et al. 2009). Furthermore, the model had already been operationalized with data from TIMSS 2011 and thoroughly tested empirically (Erberer et al. 2015).

Following the example of (Erberer et al. 2015), the dependent variable is a binary indicator for Academic Success in mathematics in TIMSS 2011. Academic Success was accordingly defined as performance, at or above the mean achievement score for disadvantaged students within each education system (see below the description of the variable disadvantaged students). Since in the TIMSS complex assessment design, student achievement was represented by five plausible value scores (mean $=500$, standard deviation $=100$ ), calculated using item response theory (see Olson et al. 2008 for details on scaling). These plausible values were then, in turn, used to create five plausible indicators of student academic success. Subsequent analysis using this variable was repeated five times (with each plausible value) and then summarized according to the formula proposed by Little and Rubin (1987).

The grouping variable, used for analysis here, indicated student status in terms of social disadvantage. A student was categorized as disadvantaged if ascribed "Few Resources" in the index, Home Educational Resources. This index is included in the TIMSS database and was created from student reports about three home resources: number of books in the home, availability of two home 
study supports and parental education (mean $=10$, standard deviation =1). Students in the category "Few Resources," on average, reported that they had 25 or fewer books in the home, neither of the two home study supports (own room and internet connection), and that neither parent had achieved more than completion of upper-secondary education (Mullis et al. 2012, p. 180).

The combination of these two variables (disadvantaged student and academic success) represents the operational definition of resilience for this study. So, according to this definition, a student was considered academically resilient if he or she simultaneously qualified according to the categories disadvantaged and academic successful. Similar approaches to operationally defined academic resilience have been adopted in other studies using international large-scale datasets, for example, Agasisti and Longobardi (2014), Cheung et al. (2013), Erberer et al. (2015), OECD (2011).

The set of independent variables and the proportion of respondents in each category is presented for each country in Table 2.

The variables in the table above can be roughly grouped into student and school characteristics, and both groups would fit into the individual, micro- and meso-systems. However, as will be discussed later, it was hypothesized that cultural beliefs and values associated with these variables (i.e., macro-system) are important in their influence on student academic achievement.

\section{Results}

Following the methodology described above, in the first step, country-specific models were estimated with all covariates included, accounting for heterogeneity of variance between disadvantaged and non-disadvantaged students. Estimates of the natural logarithm of the variance ratio for disadvantaged to non-disadvantaged students (log sigma) are shown in Table 3.

The log sigma estimate was negative in four cases and only positive in one. Nevertheless, in all cases, it proved nonsignificant. A negative log sigma value implies that students with more resources are characterized by lower variability in their achievement. However, nonsignificant values indicate that differences in achievement variability between disadvantaged and non-disadvantaged students are negligible (controlling for other variables in the model).

In the next step, variables were included in the countryspecific models that showed at least marginal impact on academic success depending on disadvantage status. In order to do this, interaction terms between the variable disadvantaged and selected explanatory variables were included. ${ }^{6}$ Estimates are presented in Table 4.
In reference to the first objective, i.e., identification of factors and conditions associated with academic success, not all factors expected to co-vary with differences in educational achievement emerged as significant predictors of resilience. For example, size of school catchment population (a proxy variable for rural or urban location) only showed significant association with success in Chinese Taipei. However, this might be explained by the fact that the five countries analyzed reported very few schools in towns with fewer than 15,000 inhabitants (between 0 and $5 \%$, while the TIMSS international average is $35 \%$ ). Additionally, the results suggested that school emphasis on academic success had very little association with academic achievement for either disadvantaged or non-disadvantaged students. This factor only proved positive in association with academic success in Japan. This finding might be explained by the high social value placed on education in these five countries (as reported in the TIMSS Encyclopedia, Mullis et al. 2012). That is, as most schools tended to report great emphasis on academic success, low variation of this variable would not allow observation of any significant effect on student achievement. In fact, according to the TIMSS International Report, only Hong Kong, of the five countries analyzed here, reported School Emphasis on Academic Success at a level below the international average (Mullis et al. 2012). Gender of students also showed no significant association with achievement in mathematics; however, as will be discussed later, a differential effect for advantaged and disadvantaged children in Korea was evident. Finally, shortages in mathematics resources did not show a significant association with likelihood of academic success. Again, this somehow surprising result might be explained by the low variation of this variable, since schools in these education systems are not normally affected by resource shortages (Mullis et al. 2012).

Among the variables showing a significant relationship with academic achievement, a pattern emerged which was related to the value students placed on education and student and teacher educational expectations. This strongly conformed with the findings of previous studies (e.g., Ho 2009; Jerrim 2015; Shin et al. 2009). For example, students reporting the high value of mathematics were much more likely to become high achievers in Taipei, Hong Kong, Japan and Korea. The only exception was Singapore where it was not a significant predictor of success. Student academic expectation was an important predictor for high achievement in all educational systems. Those who reported their expectation of finishing college or above were much more likely to score well in mathematics. With

\footnotetext{
${ }^{6}$ Detailed results of the selection of indicators for countries subject to analysis are available upon request.
} 
Table 2 Independent variables used in the analysis and proportion of respondents in each category for each country

\begin{tabular}{|c|c|c|c|c|c|c|c|}
\hline Variable & Description & $\begin{array}{l}\text { Response } \\
\text { categories }\end{array}$ & $\mathrm{CT}$ & HK & JP & RK & $S$ \\
\hline \multirow[t]{3}{*}{$\begin{array}{l}\text { Parental level of } \\
\text { education }\end{array}$} & \multirow[t]{3}{*}{ Highest level of education of either parent. } & $\begin{array}{l}\text { Lower sec. or } \\
\text { less }\end{array}$ & 0.13 & 0.29 & 0.03 & 0.03 & 0.15 \\
\hline & & $\begin{array}{l}\text { Upper } \\
\text { secondary }\end{array}$ & 0.46 & 0.45 & 0.34 & 0.41 & 0.28 \\
\hline & & Post-secondary & 0.41 & 0.26 & 0.64 & 0.57 & 0.57 \\
\hline \multirow{2}{*}{$\begin{array}{l}\text { Positive teacher } \\
\text { expectations }\end{array}$} & \multirow{2}{*}{$\begin{array}{l}\text { Students' answers to the question: Do you agree that your teacher } \\
\text { thinks you can do well in mathematics lessons? }\end{array}$} & Disagree & 0.82 & 0.58 & 0.88 & 0.67 & 0.34 \\
\hline & & Agree & 0.18 & 0.42 & 0.12 & 0.33 & 0.66 \\
\hline \multirow[t]{3}{*}{$\begin{array}{l}\text { Educational } \\
\text { expectations }\end{array}$} & \multirow[t]{3}{*}{ Students' reports on the level of education they would like to attain } & $\begin{array}{l}\text { Less than } \\
\text { university }\end{array}$ & 0.25 & 0.23 & 0.51 & 0.15 & 0.16 \\
\hline & & $\begin{array}{l}\text { University } \\
\text { degree }\end{array}$ & 0.48 & 0.45 & 0.47 & 0.67 & 0.50 \\
\hline & & Masters or $\mathrm{PhD}$ & 0.27 & 0.32 & 0.02 & 0.18 & 0.33 \\
\hline \multirow{3}{*}{$\begin{array}{l}\text { Student bullied at } \\
\text { school }\end{array}$} & \multirow{3}{*}{$\begin{array}{l}\text { Students' responses on how often they experienced six bullying } \\
\text { behaviors. For example, "I was made fun of or called names" }\end{array}$} & Almost never & 0.67 & 0.54 & 0.63 & 0.65 & 0.52 \\
\hline & & About monthly & 0.26 & 0.36 & 0.28 & 0.28 & 0.36 \\
\hline & & About weekly & 0.07 & 0.10 & 0.09 & 0.07 & 0.12 \\
\hline \multirow[t]{3}{*}{$\begin{array}{l}\text { School discipline } \\
\text { and safety }\end{array}$} & \multirow{3}{*}{$\begin{array}{l}\text { School principals' perceptions about the degree to which eleven } \\
\text { behaviors are a problem in their schools. For example: "Classroom } \\
\text { disturbance," "Cheating" }\end{array}$} & $\begin{array}{l}\text { Hardly any } \\
\text { problem }\end{array}$ & 0.64 & 0.51 & 0.46 & 0.38 & 0.51 \\
\hline & & Minor problems & 0.35 & 0.49 & 0.35 & 0.50 & 0.49 \\
\hline & & $\begin{array}{l}\text { Moderate } \\
\text { problems }\end{array}$ & 0.01 & 0.01 & 0.20 & 0.13 & 0.00 \\
\hline \multirow{3}{*}{$\begin{array}{l}\text { Population where } \\
\text { the school is } \\
\text { located }\end{array}$} & \multirow[t]{3}{*}{$\begin{array}{l}\text { Answers of school principals to the question: How many people live } \\
\text { in the city, town, or area where your school is located? }\end{array}$} & $\begin{array}{c}\text { More than } \\
100,000\end{array}$ & 0.63 & 0.88 & 0.67 & 0.87 & 1.00 \\
\hline & & $15,001-100,000$ & 0.34 & 0.09 & 0.27 & 0.10 & 0.00 \\
\hline & & 15,000 or less & 0.03 & 0.03 & 0.05 & 0.03 & 0.00 \\
\hline \multirow{2}{*}{$\begin{array}{l}\text { Lack of school } \\
\text { resources }\end{array}$} & \multirow{2}{*}{$\begin{array}{l}\text { Whether school principals consider that instruction in their schools is } \\
\text { affected by shortages in twelve school and classroom resources. For } \\
\text { example: "instructional materials," "heating/cooling" }\end{array}$} & Not affected & 0.33 & 0.41 & 0.38 & 0.58 & 0.67 \\
\hline & & Affected & 0.67 & 0.59 & 0.62 & 0.42 & 0.33 \\
\hline \multirow{3}{*}{$\begin{array}{l}\text { \% Disadvantaged } \\
\text { students at } \\
\text { school }\end{array}$} & \multirow{3}{*}{$\begin{array}{l}\text { Answers of school principals to the question: Approximately what } \\
\text { percentage of students in your school come from economically } \\
\text { disadvantaged homes? }\end{array}$} & $0-25 \%$ & 0.86 & 0.42 & 0.84 & 0.68 & 0.89 \\
\hline & & $26-50 \%$ & 0.10 & 0.28 & 0.14 & 0.22 & 0.09 \\
\hline & & $\begin{array}{l}\text { More than } \\
50 \%\end{array}$ & 0.03 & 0.30 & 0.02 & 0.10 & 0.02 \\
\hline \multirow{2}{*}{$\begin{array}{l}\text { School emphasis } \\
\text { on academic } \\
\text { success }\end{array}$} & \multirow{2}{*}{$\begin{array}{l}\text { School principals' perceptions on five aspects of academic optimism. } \\
\text { For example: "Teachers' expectations for student achievement," } \\
\text { "Parental support for student achievement," and "Students' desire } \\
\text { to do well in school" }\end{array}$} & $\begin{array}{l}\text { Medium } \\
\text { emphasis }\end{array}$ & 0.07 & 0.47 & 0.47 & 0.28 & 0.29 \\
\hline & & High emphasis & 0.93 & 0.53 & 0.53 & 0.72 & 0.71 \\
\hline \multirow[t]{2}{*}{ Sex } & \multirow[t]{2}{*}{ Students' answers to the question: Are you a girl or a boy" } & Girl & 0.48 & 0.49 & 0.50 & 0.52 & 0.49 \\
\hline & & Boy & 0.52 & 0.51 & 0.50 & 0.48 & 0.51 \\
\hline \multirow[t]{2}{*}{ Language of test } & \multirow[t]{2}{*}{$\begin{array}{l}\text { Students' responses to the question: How often do you speak } \\
<\text { language of test }>\text { at home? }\end{array}$} & $\begin{array}{l}\text { Always or } \\
\text { almost always }\end{array}$ & 0.92 & 0.80 & 0.99 & 1.00 & 0.57 \\
\hline & & $\begin{array}{l}\text { Sometimes or } \\
\text { never }\end{array}$ & 0.08 & 0.21 & 0.01 & 0.00 & 0.43 \\
\hline \multirow[t]{3}{*}{ Math homework } & \multirow[t]{3}{*}{ Time a student devotes to math homework during average week } & More than $3 \mathrm{~h}$. & 0.17 & 0.17 & 0.03 & 0.02 & 0.16 \\
\hline & & $45 \mathrm{~min}$. to $3 \mathrm{~h}$. & 0.45 & 0.45 & 0.20 & 0.20 & 0.57 \\
\hline & & $<45 \min$ & 0.38 & 0.38 & 0.77 & 0.78 & 0.27 \\
\hline
\end{tabular}

$C T$ Chinese Taipei, $H K$ Hong Kong, $J P$ Japan, $R K$ Republic of Korea, $S$ Singapore

the exception of Hong Kong and Japan, there was significant association between teacher expectations and student success.
Impact of the test language being spoken at home was significant to student performance in three educational systems (Chinese Taipei, Hong Kong and Singapore). In 
Table 3 Heterogeneity of variance for academic success between groups of disadvantaged and non-disadvantaged students

\begin{tabular}{|c|c|c|c|c|c|c|c|c|c|c|}
\hline & \multicolumn{2}{|c|}{ Chinese Taipei } & \multicolumn{2}{|c|}{ Hong Kong } & \multicolumn{2}{|l|}{ Japan } & \multicolumn{2}{|l|}{ Korea } & \multicolumn{2}{|c|}{ Singapore } \\
\hline & Coeff. & SE & Coeff. & SE & Coeff. & SE & Coeff. & SE & Coeff. & SE \\
\hline $\operatorname{Ln}(\sigma)$ & -0.18 & 0.18 & -0.03 & 0.14 & 0.16 & 0.37 & -0.24 & 0.54 & -0.72 & 0.53 \\
\hline
\end{tabular}

Table 4 Country-specific estimates of logistic regression coefficients in models for academic success-taking into account heterogeneity of variance between disadvantaged and non-disadvantaged students

\begin{tabular}{|c|c|c|c|c|c|c|c|c|c|c|}
\hline & \multicolumn{2}{|c|}{ Chinese Taipei } & \multicolumn{2}{|c|}{ Hong Kong } & \multicolumn{2}{|l|}{ Japan } & \multicolumn{2}{|l|}{ Korea } & \multicolumn{2}{|c|}{ Singapore } \\
\hline & Coeff. & SE & Coeff. & SE & Coeff. & SE & Coeff. & SE & Coeff. & SE \\
\hline Sex_girl & -0.01 & 0.09 & -0.12 & 0.15 & 0.01 & 0.12 & 0.07 & 0.10 & 0.02 & 0.06 \\
\hline Student bullied_almost never & -0.31 & 0.36 & 0.12 & 0.23 & 0.15 & 0.22 & 0.10 & 0.26 & $0.23 *$ & 0.14 \\
\hline Student bullied_about monthly & -0.02 & 0.40 & 0.27 & 0.21 & 0.27 & 0.27 & 0.12 & 0.25 & 0.20 & 0.13 \\
\hline Student value mathematics_value & $0.66^{* * *}$ & 0.22 & $0.95^{* * *}$ & 0.19 & 0.34 & 0.32 & $1.15 * *$ & 0.51 & 0.05 & 0.09 \\
\hline Student value mathematics_somewhat value & $0.63 * * *$ & 0.11 & $0.48 * * *$ & 0.11 & $0.49 * *$ & 0.20 & $0.61 * *$ & 0.28 & 0.00 & 0.08 \\
\hline School disc. and safety_hardly any problems & 0.17 & 0.56 & - & - & $0.66 * *$ & 0.32 & $0.47 *$ & 0.26 & - & - \\
\hline School disc. and safety_minor problems & 0.13 & 0.58 & - & - & $0.40 *$ & 0.24 & $0.42 *$ & 0.22 & - & - \\
\hline Positive teacher expectations_agree & $0.71 * * *$ & 0.18 & 0.17 & 0.13 & 0.66 & 0.45 & $0.90 * *$ & 0.41 & $0.28 *$ & 0.16 \\
\hline Lack of school resources_agree & -0.06 & 0.13 & 0.27 & 0.25 & -0.09 & 0.23 & 0.02 & 0.10 & 0.03 & 0.12 \\
\hline$\%$ disadvantaged students in school_26 to $50 \%$ & -0.13 & 0.19 & -0.30 & 0.33 & -0.01 & 0.23 & $-0.32 *$ & 0.19 & -0.36 & 0.24 \\
\hline$\%$ disadvantaged students in school_above $50 \%$ & $-0.96 * * *$ & 0.32 & $-1.08 * * *$ & 0.34 & -0.39 & 0.51 & -0.16 & 0.20 & -0.02 & 0.28 \\
\hline Educational expectations_college & $0.88 * * *$ & 0.15 & $0.81 * * *$ & 0.20 & $1.54 * * *$ & 0.57 & $0.73 * *$ & 0.34 & 0.16 & 0.11 \\
\hline Educational expectations_postgrade & $1.60 * * *$ & 0.32 & $1.10^{* * *}$ & 0.21 & - & - & $0.81 *$ & 0.45 & $0.41^{*}$ & 0.23 \\
\hline $\begin{array}{l}\text { School Emphasis on Academic Success_high or very } \\
\text { high }\end{array}$ & 0.30 & 0.28 & 0.44 & 0.27 & $0.44 *$ & 0.26 & 0.06 & 0.11 & 0.19 & 0.17 \\
\hline Language of test_always or almost always & $0.68 * * *$ & 0.16 & $-0.40 *$ & 0.21 & 0.81 & 0.73 & 0.57 & 0.72 & $0.13 *$ & 0.07 \\
\hline Parental level of education_above upper secondary & $0.43 * * *$ & 0.14 & 0.03 & 0.18 & $0.44 *$ & 0.23 & $0.56 * *$ & 0.26 & 0.16 & 0.11 \\
\hline $\begin{array}{l}\text { Parental level of education_lower secondary or } \\
\text { below }\end{array}$ & -0.13 & 0.13 & -0.01 & 0.16 & -0.62 & 0.43 & -0.21 & 0.24 & $-0.17 *$ & 0.10 \\
\hline Population_medium & $-0.30 * *$ & 0.14 & - & - & -0.15 & 0.25 & -0.08 & 0.20 & - & - \\
\hline Population_small & -0.14 & 0.27 & - & - & 0.01 & 0.43 & -0.53 & 0.40 & - & - \\
\hline Homework math_over $3 \mathrm{~h}$ a week & -0.18 & 0.14 & 0.34 & 0.23 & 0.03 & 0.64 & -0.60 & 0.40 & 0.05 & 0.09 \\
\hline Homework math_less than 45 min a week & $-0.51 * * *$ & 0.12 & $-0.62 * * *$ & 0.16 & 0.09 & 0.18 & 0.02 & 0.12 & $-0.33^{*}$ & 0.19 \\
\hline Disadvantaged_no & -0.24 & 0.36 & $0.36^{*}$ & 0.19 & $0.93 *$ & 0.48 & 0.27 & 0.43 & $0.43^{*}$ & 0.24 \\
\hline Constant & -0.84 & 0.62 & -0.04 & 0.50 & $-1.62 *$ & 0.95 & -1.22 & 1.11 & -0.53 & 0.34 \\
\hline Non-disadvantaged*student bullied_almost never & $0.92 * *$ & 0.38 & - & - & - & - & - & - & - & - \\
\hline Non-disadvantaged*student bullied_about monthly & 0.57 & 0.45 & - & - & - & - & - & - & - & - \\
\hline Disadvantaged*sex_girl & - & - & - & - & - & - & $-1.02 * *$ & 0.51 & - & - \\
\hline Disadvantaged*educational expectations_college & - & - & - & - & - & - & - & - & $0.87 * * *$ & 0.26 \\
\hline Disadvantaged*educational expectations_postgrad & - & - & - & - & - & - & - & - & 0.08 & 0.39 \\
\hline Disadvantaged*math homework_over $3 \mathrm{~h}$ a week & - & - & - & - & - & - & - & - & $0.54 * *$ & 0.28 \\
\hline $\begin{array}{l}\text { Disadvantaged*math homework less than } 45 \text { min a } \\
\text { week }\end{array}$ & - & - & - & - & - & - & - & - & -0.50 & 0.31 \\
\hline
\end{tabular}

*** Indicates significance at 0.01 level, ** at 0.05 level and * at 0.1 level

Taipei and Singapore, the association was positive, while it was negative in Hong Kong. Considering this variable a proxy for immigration, given that immigrant students are more likely to be socially disadvantaged (Cheung et al. 2013), this negative association between "speaking the test language at home" and academic success in Hong Kong 
seems counterintuitive. However, this pattern may have been previously described as a phenomenon known as "academic redshirting." 7 That is, the practice of deliberatively enrolling immigrant children into a lower grade to improve their ability to compete in school. According to Pong (2009), immigrant parents (mainly from Mainland China) often employ this strategy with the encouragement of school authorities, since school administrators have an incentive to avoid apparent reduction in overall school achievement. Despite the fact that grade retention is discouraged during the first 9 years of free and universal primary and junior secondary education in Hong Kong, immigrant parents can select grade level for their children when they first enter school in Hong Kong (Pong 2009). So, as a result of this practice, immigrant students generally have more years of schooling than their non-immigrant peers.

In Taipei and Hong Kong, composition of schools was also significant. Students attending schools with fewer disadvantaged students were much more likely to achieve academic success than those at schools with a large proportion of disadvantaged students. With the exception of Taipei, status with respect to social disadvantage was an important predictor for high achievement. Odds for students in Hong Kong, Japan and Singapore becoming academically successful were three times higher for those NOT from disadvantaged homes. This general pattern also resembled results from previous studies (see, e.g., Borman and Overman 2004; Erberer et al. 2015; Mullis et al. 2012; OECD 2005).

Parental education seemed significant in three educational systems-Chinese Taipei, Japan and Korea. A significant difference was particularly visible, when parents' education was above upper secondary level. Academic experience of parents clearly stimulated achievement. It is also essential to note that learning time plays a crucial role in academic achievement of students. Although the discriminatory power of the indicator-time per week spent on mathematics homework-was not high, results clearly demonstrated that in three educational systems (Chinese Taipei, Hong Kong and Singapore), little time spent on math homework was associated with poor achievement. The results demonstrated that homework set for over 3 hours a week did not substantially improve achievement in mathematics.

In relation to the second objective, the following set of country-specific predictors was identified as differentiated

\footnotetext{
7 The term 'redshirting' was first coined on the athletics field, when college coaches asked their student-athletes to defer by one or more semesters in order to grow physically or until the athlete had improved their skills.
}

examples of influence on academic success determined by status of disadvantage.

In Taipei, non-disadvantaged groups tended to be significantly influenced by bullying. Odds for high achievement increased by as much as $150 \%$ in the group of students from non-disadvantaged homes if they never experienced bullying, as compared with those who were bullied on a weekly basis. This result suggests stronger effects from bullying are experienced by students from non-disadvantaged families. A possible interpretation of this pattern might be that non-disadvantaged students are less accustomed to forms of physical or psychological violence and therefore suffer correspondingly greater impact.

In Hong Kong and Japan, no single indicator proved differential for either group, i.e., disadvantaged and nondisadvantaged students. This might imply that those factors influencing achievement of disadvantaged students also influenced achievement of other students.

The situation in Korea was unique. Here, only gender was differential in its influence; the odds for being in the group of high achievers while being disadvantaged were about $64 \%$ lower for girls. This result is not completely surprising given the small but significant difference in the overall average achievement between boys and girls in Korea. ${ }^{8}$ However, the magnitude of the difference suggests an important gender gap for socially disadvantaged students. In this sense, this analysis suggested that positive outcomes from relatively recent policies implemented in Korea that had been intended to close the persistent gender gap in Mathematics was not extrapolated to disadvantaged students. That means, for example, that disadvantaged students were impervious to the more female-friendly mathematics curriculum or the more gender-neutral language which had been introduced to text books (OECD 2010).

Finally, in Singapore, two factors proved significant in the differentiation of achievement between disadvantaged and non-disadvantaged students: student expectation in terms of final level of education and time spent on mathematics homework. Results suggested that students from disadvantaged backgrounds who expected to finish 2 or 4 year college were much more likely to achieve academically than their counterparts from non-disadvantaged homes with the same expectations (i.e., they were more resilient) —odds ratios for high achievement in these two groups were above 2 . It might be hypothesized, however, that given the high value placed on education in

\footnotetext{
8 According to the TIMSS Mathematics International Report, the difference in Mathematics achievement between boys and girls is statistically significant and amounts to 6 score points (Mullis et al. 2012, p. 70).
} 
Singaporean society (Byun and Park 2012; Mullis et al. 2012), students from non-disadvantaged backgrounds rarely aimed below college (failure to do so might even be negatively interpreted by a student's family or friends), while for those from disadvantaged backgrounds, ambition to finish college was an important indicator for their academic achievement. Only the reaction of the Singaporean educational system seemed differentiated in terms of time spent on mathematics homework. The results showed that odds for high achievement increased almost threefold for disadvantaged students spending over $3 \mathrm{~h}$, compared with peers' less than $45 \mathrm{~min}$ a week, on mathematics homework.

\section{Conclusions}

This study set out to identify factors and conditions associated with academic success in Taipei, Hong Kong, Japan, Korea and Singapore and to differentiate with respect to factors limited to association with the academic success of socially disadvantaged students (i.e., academic resilience). Further, a cultural-ecological transactional perspective was applied to help explain processes underlying academic resilience in these countries.

In terms of the first objective, no consistent patterns between countries were identified. The analysis identified a set of factors and conditions that proved important as predictors for academic success in these education systems. These factors included positive student attitude to mathematics, teacher confidence in student performance and speaking the test language at home. In high performing East Asian education systems, little evidence could be found to support the importance of emphasis on academic success, population of the school catchment area or shortages in school resources. In these education systems, close to equal conditions prevailed and gender differences in terms of achievement were mostly absent, (with the clear exception of disadvantaged students in Korea).

In the scope of the second objective, only a few differentiating factors were identified as associated with student disadvantage. In Hong Kong and Japan, no single factor was exclusively associated with socially disadvantaged student success academically. Nevertheless, this should not undermine targeting of policy. It might be stated that factors positively associated with academic achievement are still likely to stimulate academic resilience if applied exclusively to disadvantaged students.

With respect to factors that might be regarded as promoters of academic resilience, student academic expectations and the amount of time spent on mathematics homework in Singapore were more strongly associated with higher probabilities of academic success for disadvantaged students. In Korea, student gender, in particular, was identified with boys' resilience. Drawing on the cultural-ecological transactional perspective proposed by (Kuperminc et al. 2009), on the evidence of this study, it can be stated that the three variables, student academic expectations, the extent to which students work at home and gender, have important attached cultural beliefs and values. In Singapore, the finding that student academic expectations and the extent to which they work on mathematics were both significantly associated with academic resilience, as argued above and might be explained by the influence of Confucianism and collectivism. Following the analysis of Stankov (2010), Confucian Asian cultures, such as the Singaporean, have a long tradition of high regard for learning and emphasis on effort to achieve academically; moreover, collectivism is expressed in family closeness and social harmony. These two features of culture in Singapore lead to an impression that students strive to achieve not only for their personal success but also for the honor of family and society. Taking this reasoning further, Singaporean students might take the implications and consequences of their academic success and failure more seriously, as they are more likely to be under social pressure to succeed academically. Finally, in Korea, despite the recent implementation of relatively successful policies aimed at reduction of gender-related education gaps in mathematical achievement, girls are less likely to be academically resilient than boys, which might also be explained by cultural traits in Korean society. As Chun and colleagues pointed out, Korea, like other East Asian Confucian countries, is highly gender differentiated ${ }^{9}$ and despite an outer façade of modern characteristics and social change, both family and social life are still founded on traditional gender relations (Chun et al. 2008, pp. 989). Furthermore, authors like Sung (2003) have noted that Confucian ideology regarding gender roles remain especially strong at family level (e.g., the male as the positive being-yang, and the female as its negative counterpartying).

Beyond the above implications for policy and practice, the authors believe that results were methodologically and theoretically relevant. In methodological terms, a heterogeneous choice framework for logistic regression models was demonstrated to differentiate between factors for academic resilience and general academic achievement. In the analysis of educational resilience in collectivist countries, the relevance of the theoretical cultural-ecological transaction model was demonstrated.

There were, however, several limitations to the study. First, results require confirmation on a broader sample of

\footnotetext{
${ }_{9}$ Korea ranked 117 th out of 142 countries in the last edition of the Global Gender Gap Index (Hausmann 2014).
} 
countries. Further analysis using the same statistical and theoretical approaches should be applied to other groups of countries with similar or contrasting cultural characteristics, for example collectivist societies in Latin America or individualistic Western societies. Second, it is not clear whether home educational resources are the only factor responsible for heterogeneity of variance in high achievement. Third, given the cross-sectional nature of the data, our results cannot be interpreted in a causal fashion. Finally, it is also not clear why the same set of variables produced widely differing results in the countries analyzed. It is acknowledged that this phenomenon demands future research, probably by exploiting methods better suited to exposure of mechanisms underlying the patterns highlighted by this study (e.g., qualitative case studies).

Acknowledgments Authors would like to thank three reviewers for their substantial comments leading to improvement of the paper. Remaining errors are ours. Both Authors declare that they contributed to the paper equally.

Open Access This article is distributed under the terms of the Creative Commons Attribution 4.0 International License (http://crea tivecommons.org/licenses/by/4.0/), which permits unrestricted use, distribution, and reproduction in any medium, provided you give appropriate credit to the original author(s) and the source, provide a link to the Creative Commons license, and indicate if changes were made.

\section{References}

Agasisti, T., \& Longobardi, S. (2014). Educational institutions, resources, and students' resiliency: an empirical study about OECD countries. Economics Bulletin, 34(2), 1055-1067.

Allison, P. D. (1999). Comparing logit and probit coefficients across groups. Sociological Methods and Research, 28(2), 186-208.

Borman, G. D., \& Overman, L. T. (2004). Academic resilience in mathematics among poor and minority students. The Elementary School Journal, 104(3), 177-195.

Bronfenbrenner, U. (1979). The ecology of human development. Cambridge: Harvard University Press.

Byun, S., \& Park, H. (2012). The academic success of East Asian American youth: The role of shadow education. Sociology of Education, 85(1), 40-60.

Cheung, K., Sit, P., Soh, K., Ieong, M., \& Mak, S. (2013). Predicting academic resilience with reading engagement and demographic variables: Comparing Shanghai, Hong Kong, Korea, and Singapore from the PISA perspective. The Asia-Pacific Education Researcher, 23(4), 895-909.

Chun, H., Khang, Y. H., Kim, I. H., \& Cho, S. I. (2008). Explaining gender differences in ill-health in South Korea: The roles of socio-structural, psychosocial, and behavioral factors. Social science \& medicine, 67(6), 988-1001.

Erberer, E., Stephens, M., Mamedova, S., Ferguson, S. \& Kroeger, T. (2015). Socioeconomically disadvantaged students who are academically successful: Examining academic resilience crossnationally. IEA Policy Brief Series, (5).

Graves, D. (2014). Black high school students' critical racial awareness, school-based racial socialization, and academic resilience. Berkeley Review of Education, 5(1), 217-220.
Hausmann, R. (2014). Gender gap report 2014. Geneve: World Economic Forum.

Hill, R. (1958). Generic features of families under stress. Social Casework, 39, 139-150.

Ho, E. S. (2009). Characteristics of East Asian learners: What we learned from PISA. Educational Research Journal, 24(2), 327-348.

Hofstede, G. (1984). Cultural dimensions in management and planning. Asia Pacific Journal of Management, 1(2), 81-99.

Jerrim, J. (2015). Why do East Asian children perform so well in PISA? An investigation of Western-born children of East Asian descent. Oxford Review of Education, 41(3), 310-333.

Kuperminc, G., Wilkins, N., Roche, C., \& Álvarez Jiménez, A. (2009). Risk, resilience and positive development among Latino youth. In J. M. Grau, F. A. Villarruel, T. J. Chahin, N. J. Cabrera, \& M. Azmitia (Eds.), Handbook of U.S. Latino psychology: Developmental and community-based perspectives (pp. 213-233). Thousand Oaks: Sage.

Little, R. J. A., \& Rubin, D. B. (1987). Statistical analysis with missing data. New York: Wiley.

Martin, A. J., \& Marsh, H. W. (2006). Academic resilience and its psychological and educational correlates: A construct validity approach. Psychology in the Schools, 43(3), 267-281.

Mullis, I. V., Martin, M. O., Foy, P. \& Arora, A. (2012). TIMSS 2011 International results in mathematics. Chestnut Hill, MA: TIMSS \& PIRLS International Study Center Lynch School of Education, Boston College.

Mullis, I. V., Martin, M. O., Minnich, C. A., Stanco, G. M., Arora, A., Centurino, V. A. \& Castle, C. E. (2012). TIMSS 2011 Encyclopedia: Education Policy and Curriculum in Mathematics and Science. Chestnut Hill, MA: TIMSS \& PIRLS International Study Center Lynch School of Education, Boston College.

Mullis, I. V., Martin, M. O., Ruddock, G. J., O'Sullivan, C. Y., \& Preuschof, C. (2009). TIMSS 2011 Mathematics Framework. Chestnut Hill, MA: TIMSS \& PIRLS International Study Center Lynch School of Education, Boston College.

OECD. (2005). School factors related to quality and equity: Results from PISA 2000. Paris: OECD Publishing.

OECD. (2011). Against the odds: Disadvantaged students who succeed in school. Paris: OECD Publishing.

Olson, J.F., Martin, M.O. \& Mullis, I.V.S. (Eds.). (2008). TIMSS 2007 Technical Report. Chestnut Hill, MA: TIMSS \& PIRLS International Study Center, Boston College.

Piña-Watson, B., Ojeda, L., Castellon, N. E., \& Dornhecker, M. (2013). Familismo, ethnic identity, and bicultural stress as predictors of Mexican American adolescents' positive psychological functioning. Journal of Latina/o Psychology, 1(4), 204.

Pong, S. L. (2009). Grade level and achievement of immigrants' children: Academic redshirting in Hong Kong. Educational Research and Evaluation, 15(4), 405-425.

Shin, J., Lee, H., \& Kim, Y. (2009). Student and school factors affecting mathematics achievement international comparisons between Korea, Japan and the USA. School Psychology International, 30(5), 520-537.

Stankov, L. (2010). Unforgiving Confucian culture: A breeding ground for high academic achievement, test anxiety and selfdoubt? Learning and Individual Differences, 20(6), 555-563.

Sung, S. (2003). Women reconciling paid and unpaid work in a confucian welfare state: The case of South Korea. Social Policy \& Administration, 37(4), 342-360.

Van Breda, A. D. (2001). Resilience theory: A literature review. Pretoria: South African Military Health.

Williams, R. (2010). Fitting heterogeneous choice models with oglm. The Stata Journal, 4, 540-567. 